\title{
Notes on Filming Dance
}

\author{
Adam Roberts
}

M

$y$ intention when first deciding to film dance was to investigate how the camera relates to human movement, and so, perhaps, to discover something in general about the nature of film itself. It was, painfully, a decision not to work with narrative for a while. Luckily, I was to work with a choreographer, Jonathan Burrows, whose work I liked very much.

To start with I asked simply: what is the difference between a piece of film action (as when, in a cinema film, a woman opens a door and goes through it), and a danced movement, which might look just the same?

What is it about the human body and the moving human body in particular? How does film look at such things?

I had also been provoked by what I believe to be a fundamental misconception about film: "How can you marvel at the human body in motion if the rhythm and movement are created by the editor, not the dancer?"1 Anne Bilson, who asked this question, is a film critic writing about the way dance has been filmed. She would seem to be saying that dance is something that film can obscure: that there is something actual, and that film serves as a means to record that actuality. The means, it would seem, diminishes the actual.

Filming dance, as I have done, where I have freely re-ordered, repeated, deleted, and elided parts of an original choreography, has convinced me that film necessarily stands in a much more complex relation to what it purports to represent. I believe that film, contrary to the conception of it expressed by Anne Bilson, is not a mimetic technology. I would go so far as to say that filmic representation has a life of its own. To steal a line, the medium is the message. ${ }^{2}$

What follows are some haphazard thoughts about film that have shaped my dancefilm work.

To put it bluntly: I believe that the proper object of dance-film is rhythm. This is not to say the rhythm of the human body in motion (though that can be part of it), but rhythm as an intersection of pulses, both tangible and intangible, on screen. As a filmmaker I have worked with the following elements in pursuit of pulse:

Bodily movements and processes;

Change of angle of view of that movement;

Selection by means of framing;

Focus pulling and camera movement;

Sequence of revelation of a body or bodies; 
Timing and placing of cuts;

Developing or hindering knowledge of geography or space;

Change of light;

Sound elements, and sound mix;

Long-term patterns that emerge only over time;

Relationships between patterns;

Observance or deviation from expectation;

Deliberate creation of confusion or clarity;

Ellipsis, elision, deletion or black out;

Placing sounds in or out of synch;

Repetition and overlap.

It seems obvious to me that the relationship between pulse and time is that a pulse provides a measure or sense of time. For me this seems inescapable because I sense the passage of time by the means of a count. ${ }^{3}$

My camera and I are good at noticing things that happen (or even things that do not happen). Either way I am inevitably looking for a countable pattern. Nothing ever happens in a vacuum - a step is always preceded by and followed by another.

It is my tendency to notice the number of steps taken, the time taken to make those steps, and/or any change in rhythm or pace. I notice when one take is faster paced than another, and always take note of whether two takes (a "take" is another shot of the same material) will match if intercut with one another in an edit. It is the work of a filmmaker to make use of any kind of pattern available, and to harness these patterns to produce a pulse, tangible or intangible, on screen.

In my second collaboration with Jonathan Burrows, Our / film (1994), I overlapped most edits - that is, briefly repeated action rather than, as is usual in film editing, observed continuity or sought to abbreviate. By means of these inserted frames and seconds of movement that had already been seen, I sought to undermine the impression that the camera somehow documented a single reality, but also to foreground the activity and contingency of filmmaking.

I would also like to mention Andrey Tarkovsky's observation: "Assembly, editing, disturbs the passage of time, interrupts it and simultaneously gives it something new. The distortion of time can be a means of giving it rhythmical expression. Sculpting in time!"

Film time and theatre time are different. There is an arduous experience of time that the dancer and the live audience know well: you cannot cross the stage faster than as quickly as possible.

Time in a film is not about what the body can do, but about what the eye, free of position, can do. The camera can be anywhere and (for lack of a better word) anywhen.

Time passing in a dance-film does not pass as it does in another kind of film.

When watching a dance-film, I don't imagine that, if someone is pacing, it is because she is waiting for anyone. The pacing is the thing. 
Could there be such a thing as an agony of suspense in a dance-film? If anyone dances on screen I have the feeling of taking time off from such worldly anxiety. ${ }^{5}$

Something about this awareness of time has led me to consider the contrast between a rest and a pause in the making of dance-films. I take a rest to be a value, something in itself. A pause is a suspension of a process. However, I have found that the difference is not always clear, that the difference becomes apparent only by comprehending the whole.

I have worked with gaps because I like the speculation induced by a gap. I'm thinking of Very and The Stop Quartet / film, both of which feature punctuation-like interruptions-black spaces of varying lengths. I expect the viewer to fill these gaps with their own thoughts: "Is everything OK? When will the pictures come back?"—or, "Suddenly I'm very aware of myself, sitting here watching that blank screen. Why?" For a filmmaker, to insert spacing is easy. It is like holding a door open for others - I am aware of the time I am taking to hold the door, and how long I may yet choose to do that, while anyone passing through does not.

\section{口n}

How might paused movement (as in The Stop Quartet / film) be contrasted with a freeze frame?

A freeze frame is where one frame is paused, or more accurately, it is a frame reproduced over and over again. Time passing (which is not interrupted) is contrasted with arrested on-screen movement. A freeze frame may look like a denial of time, but it is for me a very suspenseful reminder of time passing. A freeze frame has no relationship with photography, since it appears in context. It is not a pose that is held. It is an intrusion of mechanism, like a car that breaks down. We long for the return of movement. We are filled with anxiety, though it can be a delicious anxiety.

In a film, a fixed image of something is not like a freeze frame. A steady camera watching a stationary object: time is passing, slowly for some, too quickly for others. A stationary shot is full of expectation; we know that something will happen eventually. We are good at guessing when it will happen, because we know that suspension like this will provoke anxiety in us and in the filmmaker. Usually, it is the filmmaker that flinches first. Movement resumes.

I made The Stop Quartet / film (1996) to reflect a complete dance by Jonathan Burrows. The duration of the shots (always a wide framing of the entire stage) and the speed of the dolly movement

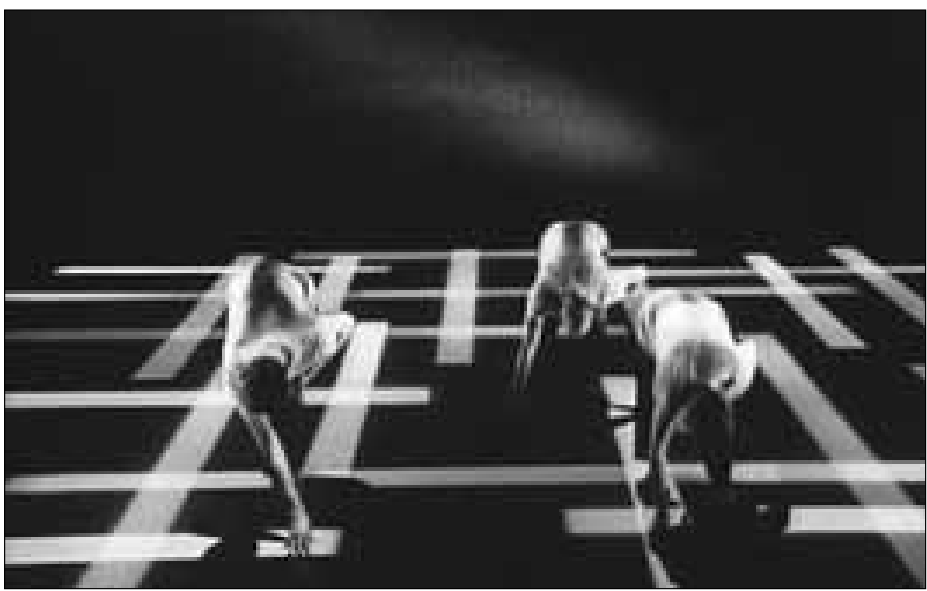

The Stop Quartet / film (1996, 16mm, 44mins) (always crabwise from left to right starting at the same place) were laid out according to a pre-determined pattern. Some passages were replaced by black, with the soundtrack continuing over. These (visual) silences were also 
organised according to a scaled version of the pattern, providing a structured punctuation. The camera movement was always very slow, such that it is apparent only during the pauses in the dance piece (the "stops" of the title). When the dancers move again, the camera movement drops from awareness.

The meshing of these various rhythmic elements interact with the structures of the dance performance to produce a new pattern, inherent only in the interaction, apprehended by the viewer but not tangible: ebbing and flowing. The effect might be compared to the phenomenon of interference fringes observed when light sources interact in the laboratory-phase is all.

The question I had set out to examine was whether tension and attention are possible without conventional montage. If it were, then in this film the forward momentum is achieved by rhythmic devices depending on proportions. "Rhythm is a matter of proportion not of accent," as the great pianist Arthur Schnabel has put it. ${ }^{6}$

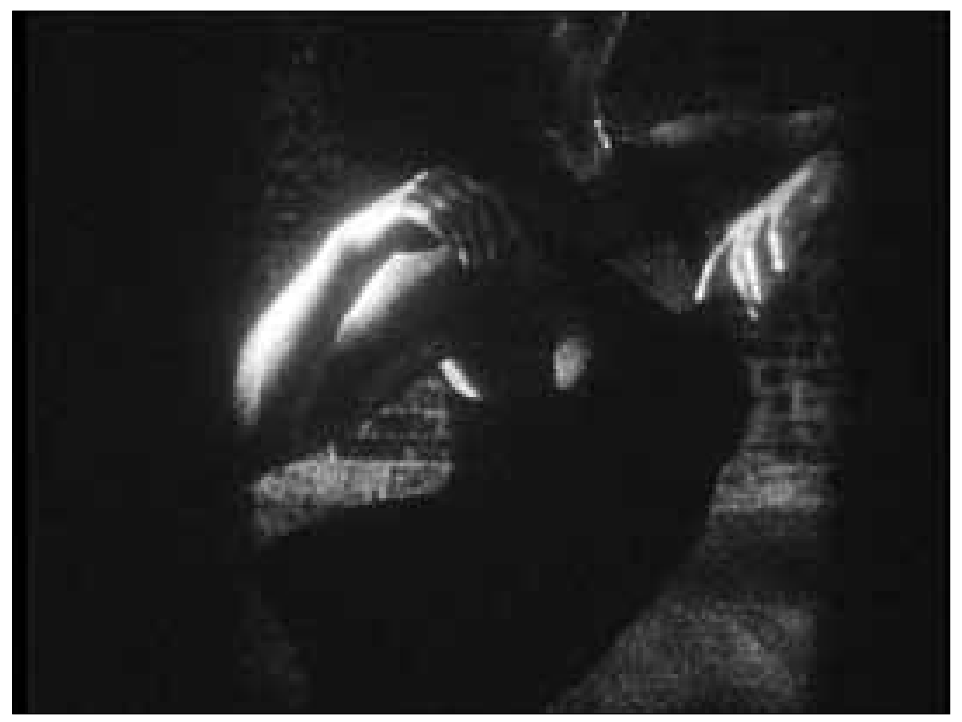

$\operatorname{Very}(1993,8 \mathrm{~mm} / 16 \mathrm{~mm}, 13 \mathrm{mins})$
My first dance-film was shot on Super-8 black-and-white film stock (Very, 1993). I enlarged the images to $16 \mathrm{~mm}$ on an optical printer so that the film grain was strongly emphasised. The materiality of the film was foregrounded.

I also filmed through a gap between two pieces of wood, so that I could create unusual framings - vertically aligned rectangles_evoking a portrait frame rather than the conventional landscape frame of cinema. I hoped that the grainy, contrasty, artfully

framed images of the dancers would make images that might vibrate with haptic sensuality (following Laura Marks' terminology).?

If dance-film exists in relation to dance, it also exists in a non-relation to narrative. It is worth thinking about what is lost, if one dispenses with narrative (conventionally understood), and about what is gained.

Film narrative depends on words, on a written script, on an unfolding of ideas that surely derives from an oral tradition. Narrative films, I think, are like a man who points off to imaginary places while saying: "let me tell you about a man who lived long ago..." For this reason, narrative films can flash back, flash forward, re-tell. We understand story telling.

Dance-film, it seems to me, is different. All I can say with such a film is:"This is happening." There is no past tense, no flash back, no future tense, no flash forward. Dance-film, I believe, 
is interesting because its components - sounds and images, gathered and rearrangedstand only for themselves. To watch Astaire and Rogers, as mentioned above, dancing in the dark, is not about where they are-in stark contrast to another kind of film that might make a hash of geography and be strongly criticised for such a fundamental mistake

When I watch a dance-film, I take everything for granted.

\section{$\square$ घ}

Thinking of Susan Sontag, I would like to say that film necessarily combines form and content; that it transcends what it seems superficially to show. "Interpretation" (as I understand Susan Sontag to have said) means to mistake content for form. She says: "By reducing the work of art to its content and then interpreting that, one tames the work of art. Interpretation makes art manageable, conformable." ${ }^{\prime \prime}$ relate this to the criticism from Anne Bilson, quoted above, which I take to be saying that dance-film is a translation of dance, or a representation of something else, an act of interpretation.

Sontag also says: "What matters ... is the pure, untranslatable, sensuous immediacy of some of its images, and ... solutions to certain problems of cinematic form."' That is what appeals to me.

I begin work on a film by contemplation of the choreography and movement. In the studio I am always struck by a happy pairing of freedom and constraint. I get a sense of freedom from the thought that every moment is unique and final, and so unprecedented and ever new. I note constraint because the dance I am witnessing takes place in a particular space and on a certain occasion. Actual bodies can only be in one place at a time. No body can become another body. The purpose of dance is served by its being actual.

Film is a very different because it must be cautious about freedom and constraint. However great the obstacle faced, the hero could quite well leap over the impossibly high wall (and does so in many a Hong Kong film), or be transported instantaneously across the world (James Bond does it all the time). Even time itself can turn back on itself (in Groundhog Day it does so over and over again). Cause can follow effect-surely the staple proposition in any detective film. Freedom is potentially unconstrained. And yet, of course, there is a limit. We, the audience, have to believe that some things are impossible. We have to believe that the bomb might go off, or the train not stop in time.

Fred Astaire had a contract that specified that he be shot head to toe. He did not think a closeup much served what he was about. In some ways this is a shame. I tend toward the view that the close-up in cinema offers a means to convey a sense of the sheer physicality of the human body, its solidity, plasticity, weight, individuality. The wider shot tends to generalise, flatten, mute. Even an inanimate object can seem alive when looked at in close-up.

I recall with such great pleasure Claire Denis's close-up of the pulse in the neck of her disgraced Sergeant as he lies inert on his bed, having contemplated and rejected suicide at the end of Beau Travail (1999)—shortly before the closing dance number, shot wide, of course. 


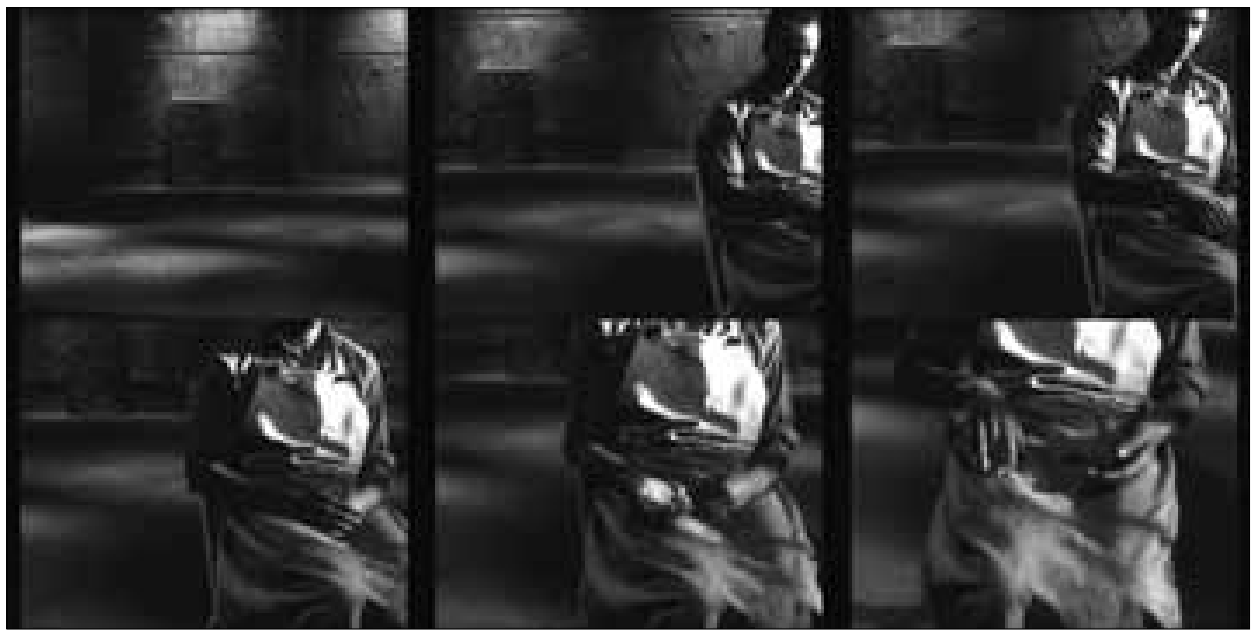

Sequence of stills, Hands (1995, 35mm, 5 mins)

In relation to Hands (1995), which begins with view of an empty space and a travelling camera that homes in on a figure, the eventual framing is a close up of a lap-at once stage, proscenium arch and domestic interior. The pulse-by means of meshing of sounds, movements and focus shifting —is drama enough to fill such a stage.

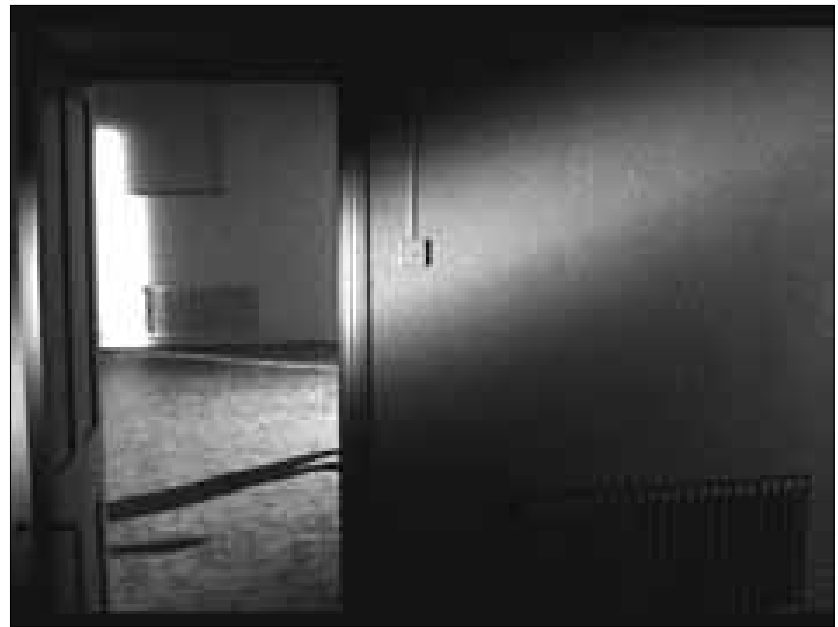

blue yellow $(1995,16 \mathrm{~mm}, 13 \mathrm{mins})$
I have always supposed that we find something most beautiful when there is the promise of more, of the thing we look at being never quite exhausted after any number of encounters. Our eyes love a beautiful thing because they "remain fixed on what remains veiled, even after the unveiling."10

Dance-film, I feel, should offer something like that: something hanging between the veiling and unveiling, something above all that resists the eternal temptation to see all, to rip open and to see into the holy of holies. A dance-film, for me, should resist impatience and literalism. It is not a record of actuality.

\section{口n}

"Your film must resemble what you see on shutting your eyes."11 


\section{References}

Bergson, Henri. Time and Free Will: An Essay on the Immediate Data of Consciousness. Translated by F.L. Pogson. London: George Allen and Unwin, 1910.

Bilson, Anne. "Hollywood has lost the art of filming good fight scenes." The Guardian. October 2, 2009. http://www.guardian.co.uk/film/2009/oct/02/hollywood-fight-scenes-ip-man.

Bresson, Robert. Notes on the Cinematographer. Trans. Jonathan Griffin. London: Quartet Books, 1975.

Curzon, Sir Clifford. Notable Twentieth-Century Pianists: A Bio-Critical Sourcebook, Vol 2. Edited by John and Anna Gillespie. Santa Barbara: Greenwood Press, 1995.

Marks, Laura U. The Skin of the Film: Intercultural Cinema, Embodiment, and the Senses. Durham: Duke University Press, 2000.

McLuhan, Marshall. Understanding Media: The Extensions of Man. New York: McGraw Hill, 1964.

Nehamas, Alexander. "The Return of the Beautiful: Morality, Pleasure and the Value of Uncertainty." Journal of Aesthetics and Art Criticism 58, no.4 (2000): 402.

Sontag, Susan. Against Interpretation and Other Essays. London: Penguin Classics, 2009.

Tarkovsky, Andrey. Sculpting in Time. Trans. Kitty Hunter-Blair. Austin: University of Texas Press, 1986.

\section{Film and Still Details}

The films made by me mentioned in this article all feature the choreography of Jonathan Burrows. For full credits, visit: www.adamroberts.eu/dancefilm.

blue/yellow (1995, 16mm, colour, 13 mins). Still shows the shadow of Sylvie Guillem.Commissioned by the BBC and France2, as a segment in Evidentia, curated by Sylvie Guillem.

Hands (1995, 35mm, b\&w, 5 mins). Sequence of stills shows Jonathan Burrows. Commissioned by the BBC and Arts Council of England.

The Stop Quartet / film (1996, 16mm, b\&w, 44mins). Still shows (I to r): Henry Montes,Jonathan Burrows, Fin Walker. Made with support from the Arts Council of Englandand The Prudential Award for the Arts.

Very (1993, 8mm optically enlarged to 16mm, b\&w 13 mins). Still shows Deborah Jones. Unfunded.

\section{Notes}

1. Bilson, "Hollywood."

2. McLuhan, Understanding Media, 7.

3. I would also like to refer to Henri Bergson's conclusion that: "Pure duration is wholly qualitative. It cannot be measured unless symbolically represented in space" (Time and Free Will, 104).

4.Tarkovsky, Sculpting in Time, 121.

5. Time and worry have never been so utterly suspended as when Fred Astaire and Cyd Charisse move from walking in the park to dancing in the dark in The Band Wagon (1953, directed by Vincente Minnelli).

6. Quoted in Curzon, Notable Twentieth-Century Pianists, 793.

7. See Marks, The Skin of the Film.

8. Sontag, Against Interpretation, 8.

9. Ibid., 9.

10. Nehamas, "The Return of the Beautiful," 402. (Nehamas is paraphrasing Nietzsche's The Birth of Tragedy ).

11. Bresson, Notes on the Cinematographer, 50. 